\title{
MATEMÁTICAS E ARQUITETURA GUARANI TAMBEOPÉ: UMA INVESTIGAÇÃO NA EDUCAÇÃO BÁSICA
}

\author{
MATHEMATICS AND ARCHITECTURE GUARANI TAMBEOPÉ: AN \\ INVESTIGATION IN BASIC EDUCATION
}

\section{MATEMÁTICAS Y ARQUITECTURA GUARANI TAMBEOPÉ: UMA INVESTIGACIÓN EM EDUCACIÓN BÁSICA}

\author{
Ana Paula Azevedo Moura* (iD) 9 \\ Ligia Arantes Sad ${ }^{* *}$ (D) 9
}

Claudia A. C. de Araujo Lorenzoni ${ }^{* * * *}$ (D) $(9$

\begin{abstract}
RESUMO
Este artigo apresenta um recorte de uma pesquisa de mestrado em Educação em Ciências e Matemática defendida em 2019, desenvolvida com uma turma de Ensino Fundamental, em diálogo com saberes e fazeres da cultura indígena Guarani Tambeopé. Reforçado pela efetivação da Lei $\mathrm{n}^{\circ}$ 11.645/2008 e embasado pelo Programa Etnomatemática, o estudo teve por objetivo principal fomentar a (re)significação da cultura indígena Guarani Tambeopé por meio da inserção de seus saberes e fazeres nas aulas de Matemática. Para tanto, desenvolvemos uma Unidade Didática em uma escola da rede municipal de Vitória - Espírito Santo, abordando, especialmente, uma investigação acerca das mba'eitxa oo djadjapo (técnicas de construções) do povo Guarani Tambeopé e das possibilidades e estratégias mais adequadas à sua incorporação às aulas de Matemática da Educação Básica. Conforme constatamos, os encontros de intervenção na escola não indígena contribuíram para a (re)significação dos conhecimentos dos educandos sobre o povo Guarani Tambeopé e seus saberes/fazeres.
\end{abstract}

Palavras-chave: Educação Básica. Povo Guarani Tampeopé. Mba'eitxa oo Djadjapo (Técnicas de construções). Programa Etnomatemática. (Re)significação.

\begin{abstract}
This article presents an excerpt of a master's research in Science and Mathematics Education defended in 2019, developed with a class of Elementary School of Basic Education in dialogue with knowledge and practices of the Guarani Tambeopé indigenous culture. Reinforced by the enactment of Law $n^{\circ}$

\footnotetext{
* Mestre em Educação em Ciências e Matemática pelo Instituto Federal do Espírito Santo (IFES). Professora de Matemática na Escola Estadual de Ensino Fundamental e Médio Vila Nova de Colares (SEDU), Serra, Espírito Santo, Brasil. Endereço para correspondência: Avenida Engenheiro Charles Bitran, 435, apto. 1006, bl. H, Jardim Camburi, Vitória, Espírito Santo, Brasil, CEP: 290092-270. E-mail: anapaula.amoura@gmail.com.

** Doutora em Educação Matemática pela Universidade Estadual Paulista Júlio de Mesquita Filho (UNESP). Professora de Matemática no Instituto Federal e Tecnológico do Espírito Santo (IFES) - Campus Vitória e do Programa de Pós-Graduação de Educação em Ciências e Matemática do IFES - Campus Vila Velha, Espírito Santo, Brasil. Endereço para correspondência: Rua Des. João Manoel de Carvalho, 140, apto. 101, Barro Vermelho, Vitória, Espírito Santo, Brasil, CEP: 29057-630. E-mail: ligia.sad@ifes.edu.br.

*** Doutora em Educação pela Universidade Federal do Espírito Santo (UFES). Professora da Coordenadoria de Matemática no Instituto Federal e Tecnológico do Espírito Santo (IFES), Vitória, Espírito Santo, Brasil. Endereço para correspondência: Rua Almirante Soído, 271, apto. 802 - Gold, Praia de Santa Helena, Vitória, Espírito Santo, Brasil, CEP: 29055-020. E-mail: claudia.araujo@ifes.edu.br.
} 
11.645/08 and based on the Ethnomathematics Program, the project's main objective was to promote a (re)signification of the Guarani Tambeopé indigenous culture through the insertion of their knowledge and practices in Mathematics classes in Basic Education. To achieve the objective, we developed a Teaching Unit in a Municipal Elementary School located in Vitória - Espírito Santo, which addressed, in particular, an investigation about the mba'eitxa oo djadjapo (construction techniques) of the Guarani Tambeopé people and the possibilities and strategies more suitable for its incorporation into Basic Education Mathematics classes. The objective of this article is the observation that the intervention meetings in the non-indigenous school contributed to the (re)signification of the students' knowledge about the Guarani Tambeopé people and their knowledge/doings.

Keywords: Basic Education. Guarani Tampeopé people. Mba'eitxa oo Djadjapo (Construction Techniques). Ethnomathematics Program. (Re) significance.

\section{RESUMEN}

Este artículo presenta un extracto de investigación de la Maestría en Educación Científica y Matemática defendida en 2019, desarrollada con una clase de la Escuela Primaria de Educación Básica en diálogo con los conocimientos y prácticas de la cultura indígena guaraní Tambeopé. Reforzado por la promulgación de la Ley $\mathrm{N}^{\circ} 11.645$ / 08 y con base en el Programa de Etnomatemática, el objetivo principal del proyecto fue promover una (re) significación de la cultura indígena guaraní Tambeopé a través de la inserción de sus conocimientos y prácticas en las clases de Matemática Educacion Basica. Para lograr el objetivo, desarrollamos una Unidad Docente en una Escuela Primaria Municipal ubicada en Vitória - Espírito Santo, que abordó, en particular, una investigación sobre las mba'eitxa oo djadjapo (técnicas de construcción) del pueblo guaraní Tambeopé y las posibilidades y estrategias más adecuadas para su incorporación a las clases de Matemática de Educación Básica. El objetivo de este artículo es observar que las reuniones de intervención en la escuela no indígena contribuyeron a la (re) significación del conocimiento de los estudiantes sobre el pueblo guaraní Tambeopé y sus saberes / hacer.

Palabras clave: Educación Básica. Pueblo Guarani Tambeopé. Mba’eitxa oo Djadjapo (Técnicas de Construcción). Programa de Etnomatemática. (Re)significado.

\section{INTRODUÇÃO}

O presente artigo é fruto de uma pesquisa de mestrado que dialogou com o povo Guarani Tambeopé, o qual vive aldeado no Espírito Santo. Responde a inquietações e angústias que se intensificaram com a oportunidade, em anos anteriores, que as pesquisadoras tiveram de vivenciar experiências interculturais em realidades indígenas ${ }^{1}$. Essas aproximações permitiram uma compreensão da luta dos indígenas por seus direitos legalmente garantidos e ajudaram a explicar a falta de entendimento a respeito da cultura indígena, mesmo que os espaços territoriais desses povos sejam parte do nosso Estado.

\footnotetext{
${ }^{1}$ Uma das autoras participou como monitora do curso de Licenciatura Intercultural de Formação de Professores Indígenas da Universidade Federal de Goiás de 2009-2013. O curso atende a alunos indígenas pertencentes a 27 etnias, em sua maior parte, professores indígenas em suas terras, situadas nos estados de Goiás, Mato Grosso, Tocantins, Maranhão e Minas Gerais, falantes de diferentes línguas. As demais autoras estabelecem contato há mais de dez anos com os indígenas do Espírito Santo, por meio de projetos junto à educação escolar.
} 
Um marco inicial na construção da pesquisa aqui relatada foi a vivência do grande desafio da educação escolar indígena de conciliar a necessidade de ensinar a matemática escolar/acadêmica, a qual não pertence ao universo indígena, e, ao mesmo tempo, dar reconhecimento e valorização aos elementos etnomatemáticos historicamente construídos em suas tradições. Esse desafio aliou-se à atuação das autoras em ensino e pesquisa, que as deixou ansiosas por realizar o caminho inverso, ou seja, abordar esses conhecimentos nas aulas de Matemática da Educação Básica por meio de um diálogo intercultural.

Na elaboração dos currículos de Matemática da Educação Básica, habitualmente, conhecimentos tidos como não acadêmicos não são levados em consideração. Possível mudança em relação a isso requer superar a perspectiva de supremacia dada, nos currículos da atualidade, a determinados conhecimentos em detrimento de outros, reconhecendo e valorizando a diversidade de saberes e fazeres que as culturas indígenas, por exemplo, possuem. A perspectiva etnomatemática considera que cada cultura, ao longo de sua história, desenvolve maneiras próprias de saber e fazer, segundo suas necessidades e seu contexto natural, concebendo a Matemática, igualmente, como produto da atividade humana em suas múltiplas dimensões (D’AMBROSIO, 2007).

No Brasil, com a Lei 11.645/2008, a temática História e Cultura Afro-Brasileira e Indígena tornou-se obrigatória em todas as disciplinas que compõem a Educação Básica, incluindo, portanto, a Matemática (BRASIL, 2008). Contudo, a proposta do trabalho realizado no âmbito da pesquisa aqui relatada não visava apenas a pôr em prática os dispositivos oficiais, mas, sobretudo contribuir com estudos voltados à superação da realidade de evidente marginalização e desconhecimento da cultura indígena. A pretensão foi de (re)significar ${ }^{2}$ o ser [indígena] pelo saber [sua história, seus costumes], com um enfoque em aspectos da cultura dos Guarani Tambeopé $e^{3}$ no Espírito Santo, a partir de um movimento dialógico com o próprio povo sobre suas técnicas de construção (Mba'eitxa oo Djadjapo, em guarani).

É importante sublinhar que a implementação da Lei 11.645/2008:

não significa beneficiar um grupo socialmente discriminado em detrimento de outro. Refere-se a tratar o desigual, já que é assim que o negro [e o indígena] vem se

\footnotetext{
2 Ao falarmos de (re)significação, embasamo-nos na compreensão da palavra significado abordada por Lins (1999), ou seja, o significado de algo é aquilo que nós dizemos sobre esse algo, um dizer que seja coerente com o que a coisa de fato é.

${ }^{3} \mathrm{O}$ grupo Guarani que vive aldeado no Espírito Santo é classificado pelos antropólogos como Guarani Mbyá. Porém, o grupo se autodenomina como Tambeopé, pelo fato de que, no passado, seus integrantes utilizavam tangas para cobrir as partes íntimas, ou seja, não andavam completamente nus, como povos de outras etnias (CARVALHO, 2013).
} 
constituindo historicamente, como desigual por um período de tempo, para que, no futuro, se possa de fato (e de direito) galgar a igualdade, pois os significados/representações, construídos na interação com o outro, pelo discurso, interferem no modo como cada um age, pensa e é (SILVA, 2009, p. 37).

O respeito à cultura, à interculturalidade, às relações interpessoais e a importância de não se impor ao outro, mas aprender com o outro, de maneira que o diálogo prevaleça, são princípios adotados durante esta e outras caminhadas realizadas pelas autoras. Mesmo porque compartilhamos a defesa de que "a sabedoria ou o conhecimento tradicional indígena promove a diversidade e reduz a incidência de doenças, estabiliza a produção de bens materiais, além de maximizar o retorno das condições simples e adaptadas" (SILVA et al., 2021, p. 7).

Nessa perspectiva, o objetivo principal foi investigar, do ponto de vista etnomatemático, baseado em D’Ambrosio (2007, 2010), estratégias didático-metodológicas que possibilitassem fomentar a (re)significação, por parte de alunos não indígenas, da cultura Guarani Tambeopé, por meio da inserção de seus saberes e fazeres em aulas de Matemática da Educação Básica, trabalho que se guiou por um viés humanizador.

\section{BASES TEÓRICAS}

No decorrer de sua história e na busca por sobrevivência, o ser humano age e reage frente a obstáculos que emergem no seu cotidiano. Nessa dinâmica, além de se apropriar de conquistas obtidas pelas gerações passadas, produz novas ferramentas ou instrumentos que possibilitam sua maior interação com o meio em que está inserido e com a natureza, os quais vão sendo transformados, ao mesmo tempo que, inevitavelmente, o homem vai se transformando e se constituindo em um ser histórico, cultural e socialmente integrado.

$\mathrm{O}$ apoderamento que o homem faz das conquistas das gerações passadas, o qual expressa as relações entre a experiência individual e a experiência social, reforça que ele:

[...] não nasce dotado das aquisições históricas da humanidade. Resultando estas do desenvolvimento das gerações humanas, não são incorporadas nem nele, nem nas suas disposições naturais, mas no mundo que o rodeia, nas grandes obras da cultura humana. Só apropriando-se delas no decurso da sua vida ele adquire propriedades e faculdades verdadeiramente humanas. Este processo coloca-o, por assim dizer, aos ombros das gerações anteriores e eleva-o muito acima do mundo animal (LEONTIEV, 1978, p. 282-283). 
D'Ambrosio (2007) pontua que, quando homens e mulheres se agrupam constituindo comunidades, desenvolvem saberes e fazeres próprios, a partir das experiências e necessidades vivenciadas, transmitindo-os aos seus descendentes. Ao longo do tempo, essa dinâmica contribui não apenas para a produção e compartilha de conhecimentos, como também para a compatibilização de comportamentos, sintetizando as características de uma cultura e influenciando a educação local, em particular a educação humanizadora.

A educação humanizadora é entendida neste estudo na perspectiva da Teoria Histórico-Cultural. Também estabelecemos conexões entre o referencial teórico da Etnomatemática e da Pedagogia Histórico-Cultural, pautando-nos na visão de D’Ambrosio (2007) e em teorias da pesquisa em Educação apresentadas em Moura (2016) como perspectivas metodológica e pedagógica, em atendimento a uma sociedade que precisa reconhecer a importância de um amplo diálogo entre culturas e perceber que "[...] diferentes modos de pensamento podem conduzir a formas diferentes de matemática" (D’AMBROSIO, 1985 apud BARTON, 2006, p. 49).

Logo, o projeto da pesquisa aqui relatada e seu desenvolvimento ampararam-se pela Etnomatemática, como programa de pesquisa que busca compreender o conhecimento do outro "através" do olhar do próprio outro, com suas múltiplas perspectivas, dando à educação um olhar mais humanizador, visto que:

O objetivo da atividade pedagógica é a transformação dos indivíduos no processo de apropriação dos conhecimentos e saberes; por meio dessa atividade - teórica e prática -, é que se materializa a necessidade humana de se apropriar dos bens culturais como forma de constituição humana (RIGON; ASBABR; MORETTI, 2010, p. 24).

Essa concepção de Educação nos faz repensar a Matemática ensinada nas escolas, mas vale ressaltar que, conforme também deixam explícitos os pesquisadores do Programa Etnomatemática, não temos como proposta rejeitar e/ou ignorar a Matemática acadêmica, visto que, por circunstâncias históricas, muitos povos obtiveram sucesso graças a esses saberes. Portanto, tivemos e temos por objetivo agregar valores de humanidade, respeito, solidariedade e cooperação, incorporando a cultura de diferentes povos à Educação Matemática, contextualizando-a, tornando-a crítica e permitindo uma nova organização da sociedade - uma sociedade mais igualitária.

O encontro intercultural pode gerar conflitos, pois uma cultura comumente deseja se impor a outra, com arrogância, superioridade e/ou prepotência (FREIRE, 2005), além da 
simples dificuldade em lidar com o desconhecido frente às bases relativamente seguras do seu próprio grupo cultural. Segundo Canclini (2009, p. 68), “em sociedades dualistas, cindidas, que continuam a segregar os índios, as políticas das diferenças são indispensáveis" na proteção de princípios culturais que cada povo considera de valor inestimável e inegociável.

Em outra via, entretanto, conhecer e assimilar culturas diferentes pode se tornar positivo, desde que as próprias raízes sejam fortes e se respeite a cultura do outro. É nesse exercício de conhecer as histórias e culturas diferentes, sem o olhar de opressão ou de desvalorização, que os escritos legais, como os que constam da Lei ${ }^{\circ} 11.645 / 2008$, podem amparar e instigar os educadores para essa mudança de discursos e práticas, lançando, no limite, o grande desafio pela convivência harmoniosa e promoção da paz nas gerações futuras.

Com o olhar para essa direção, nossa proposta de investigação foi ao encontro dos ensinamentos do educador Paulo Freire (2005), que nos convida a refletir sobre a necessidade de libertação, a qual se concretiza por meio da conscientização e da ação dos oprimidos, proporcionando, assim, não apenas sua própria libertação como também a dos opressores. Freire (2005, p. 90-91) sugere um mecanismo para se chegar a um verdadeiro diálogo: "Não é no silêncio que os homens se fazem, mas na palavra, no trabalho, na ação-reflexão. [...] $\mathrm{O}$ diálogo é este encontro dos homens, mediatizados pelo mundo, para pronunciá-lo, não se esgotando, portanto, na relação eu-tu".

Os educadores necessitam refletir sobre essas considerações para fazer de sua prática um instrumento de uma educação que proporcione meios de estabelecer relações interculturais harmoniosas, possibilitando a emergência de conhecimentos dos povos oprimidos por séculos de dominação, dentre os quais estão os indígenas e tantos outros. Trata-se, pois, de uma visão contrária à educação que tem sido, insistentemente, trabalhada nas escolas e que serve à pauta de interesses dos opressores.

Ao considerar que a paz e a produção de conhecimento estão estreitamente ligadas, a Matemática passa a ser incluída nas discussões sobre ações para a libertação dos homens. Diante dessa problemática, nossa proposta é tratar a Matemática como têm feito os pesquisadores do Programa Etnomatemática: abandonamos a visão de que ela é somente a ciência dos números e cálculos, para compreendermos que "[...] é resposta às pulsões de sobrevivência e de transcendência, que sintetizam a questão existencial da espécie humana" (D’AMBROSIO, 2007, p. 27). Ainda: 
habilidades que fazem de cada um de nós seres humanos. O acesso ao conhecimento, às relações sociais, às experiências culturais diversas podem contribuir, assim, como suporte no desenvolvimento singular do aluno como sujeito social cultural e no aprimoramento da sua vida social (LIBÂNEO, 2008, p. 160).

Uma educação que tem como objetivo a libertação dos homens não pode acontecer sem a inserção, no seu currículo, das histórias e culturas dos vários povos constituintes das sociedades nas quais essa educação é oferecida. Assim, a Educação Matemática, que "[...] em geral é determinada pela cultura na qual está situada" (BARTON, 2006, p. 41), à luz da educação humanizadora, pode considerar, nos seus currículos, os saberes e fazeres produzidos por povos de diferentes culturas na busca de explicar ou lidar com as múltiplas dimensões do ambiente (natural, social, cultural) em que vivem e, ainda, do seu imaginário. De modo contrário, sem considerar a diversidade, os fundamentos da Educação Matemática poderiam se reduzir a concepções educacionais utópicas.

A educação escolar, de um modo geral, visa a preparar o aluno não só para o mercado de trabalho, mas também para sua efetiva participação na sociedade, de forma solidária, ativa, autônoma, consciente e crítica. Sob essas considerações, em particular no que tange ao Brasil, são cada vez mais evidentes a emergência e a importância de se inserir nos currículos, de Matemática inclusive, saberes de diversas etnias indígenas - no caso do Espírito Santo, a cultura Guarani Tambeopé - que o constituem.

\section{ASPECTOS METODOLÓGICOS}

A pesquisa possui cunho etnográfico, por apresentar, intencionalmente, a necessidade de observação direta nos campos culturais envolvidos, para escuta e diálogo atento com os participantes nela envolvidos, indígenas e não indígenas. Apresenta, também, tendência metodológica à etnopesquisa crítica por meio histórico-dialético. Nesta abordagem, em especial, foram utilizadas narrativas e histórias para a produção de significados entre culturas diferenciadas - indígenas e não indígenas. Assim, caminhamos na busca por entender e interpretar os dados que foram sendo obtidos, preocupando-nos com os significados que os sujeitos atribuíam às situações vividas no seu espaço social, o que deu à investigação natureza qualitativa.

Ao abordar a pesquisa etnográfica, Lüders (2004 apud FLICK, 2009, p. 215) afirma que esta atualmente é "[...] marcada por uma participação extensiva no campo, [...] com o emprego de todos os tipos de métodos e concentrando-se na redação e na descrição das 
experiências naquele campo". No entanto, sabemos dos limites impostos pelo tempo de um curso de mestrado dedicado às investigações e, ainda, de outras variáveis que interferem na extensão da partilha sociocultural.

Com isso, o trabalho de obtenção de dados realizou-se em dois ambientes distintos, de forma paralela e articulada, que se "alimentaram" mutuamente. O primeiro ambiente foi o da pesquisa de campo em aldeias guarani na Terra Indígena Caieiras Velha II, mais especificamente na escola pública municipal guarani nela localizada, na tentativa de compreender quais as ticas de matema ${ }^{4}$, conforme propõe o Programa Etnomatemática (D’AMBROSIO, 2007), estavam presentes nas construções arquitetônicas do povo Guarani Tambeopé, o que foi feito por meio de uma postura investigativa de viés etnográficodialógico. $\mathrm{O}$ outro ambiente foi uma escola pública não indígena, situada no município de Vitória, a qual a pesquisa buscou compreender segundo a visão da própria cultura escolar, analisando quais os valores e significados os educandos, participantes da pesquisa, apresentavam sobre povos indígenas. Como Lüdke e André (2013, p. 14), assumimos que "O 'significado' que as pessoas dão às coisas e à sua vida são focos de atenção especial pelo pesquisador".

A seguir, é apresentada a caracterização desses dois ambientes de pesquisa.

\subsection{Na aldeia-campo guarani}

O grupo Guarani que vive aldeado no Estado do Espírito Santo é classificado pelos antropólogos como Guarani Mbyá. Porém, esse grupo se autodenomina como Tambeopé ou Nhandewá Tambeopé, que, no sentido literal, significa Nhande-wa'e = nossa gente, Tambeo = tanga, $p e=$ achatada/quadrada, ou seja, os que usam tanga quadrada/achatada (CARVALHO, 2013).

As Terras Indígenas do Espírito Santo localizam-se nas proximidades da Rodovia ES 010, no distrito de Santa Cruz, município de Aracruz, litoral norte do Espírito Santo. Os Tambeopé habitam três aldeias reconhecidas como área indígena: Tekoa Porã (Boa Esperança), Mboapy Pindo (Três Palmeiras) e Piraqueaçú. Contudo, existem aldeamentos guarani mais recentes, como os denominados Olho D'água e Nova Esperança, assim como

\footnotetext{
${ }^{4}$ O professor Ubiratan D'ambrosio (2007) propõe uma explicação etimológica do termo etnomatemática, sendo, então, [ticas] os modos, estilos, artes e técnicas de [matema] explicar, aprender, conhecer, lidar com [etno] o ambiente natural, social, cultural e imaginário.
} 
uma outra terra na Serra do Caparaó, que é habitada pelos Guarani, porém, sem providências legislativas.

Para o desenvolvimento do projeto de pesquisa, aproximamo-nos mais estreitamente do diretor e professores da Escola Municipal Pluridocente Indígena Aldeia Três Palmeiras, com quem identificamos o interesse conjunto em atividades que relacionassem a geometria escolar com as construções arquitetônicas do próprio povo. Assim ficou projetado o nosso objeto de pesquisa, que contribuiria não apenas para o ensino da Matemática na Educação Básica não indígena - objetivo maior da pesquisa -, como também aos interesses da educação escolar indígena. Com essa pretensão, ao pensar em termos da Matemática a ser desenvolvida, lembramos que:

\begin{abstract}
O grande desafio da Educação Indígena resulta da necessidade de se atingir simultaneamente dois grandes objetivos: preparar as populações indígenas para um convívio digno com a civilização dominante; e possibilitar aos povos indígenas a revitalização de sua identidade cultural. [...] Talvez seja menos difícil ensinar uma matemática prática, sobretudo artesanal e comercial, pois a motivação, resultante de necessidade, é grande. A exploração da matemática lúdica do ocidental - um lúdico novo, desafiador - deve também ser naturalmente atrativa. No entanto, a recuperação da dignidade cultural dos povos indígenas exige estimular seu pensar abstrato, suas ideias matemáticas próprias. Em outros termos, recuperar seus modos, maneiras, técnicas de explicar, de conhecer, de lidar com seu ambiente natural, cultural, místico. Esse é o objetivo maior da Etnomatemática (D’AMBROSIO, 1998, p. 12-13).
\end{abstract}

Assim, dedicamo-nos a conhecer as construções arquitetônicas dos Guarani Tambeopé no sentido de compreender seus modos, maneiras, técnicas de explicar, de conhecer e lidar com construções, para que, a partir dessa compreensão, pudéssemos pensar em aulas de Matemática voltadas à escola não indígena, considerando a temática "Construções Guarani". Dedicamo-nos, ainda, a pensar as atividades que seriam desenvolvidas na escola indígena, o que foi feito em acordo com os professores.

Com base nisso, caminhamos pelas aldeias Três Palmeiras, Boa Esperança e Piraqueaçu, guiadas pelo diretor indígena da escola, conhecendo as construções arquitetônicas guarani numa perspectiva etnomatemática, explorando características e técnicas construtivas, entendendo sua estrutura e importância cultural, bem como os materiais empregados, inclusive aqueles advindos do contato intercultural com o não indígena. Foi o momento em que conversamos com alguns construtores indígenas a fim de entender os significados simbólicos, materiais e imateriais de diversas de suas construções. De acordo com Itelson (2005 apud CARRINHO, 2010, p. 28), “quando os homens constroem casas, eles criam não 
só um ambiente físico, mas também um ambiente psicológico de significados, um mundo simbólico que reforça um esquema particular de gostos e valores”.

Com permissão, fotografamos 11 construções arquitetônicas, dentre elas, habitações, casa de reza e casa na aldeia temática, sendo essa última um local aberto à visitação. Na Figura 1 exibimos quatro delas.

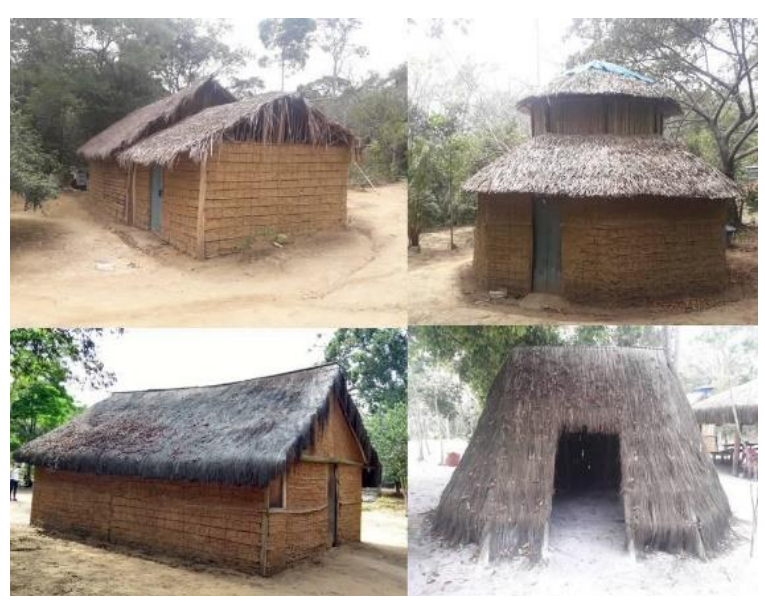

Figura 1 - Construções existentes nas aldeias Fonte: acervo das pesquisadoras (2017)

Esse foi um momento em que nós, pesquisadoras não indígenas, em contato direto com a realidade de construção indígena, produzimos significados, o que nos permitiu planejar e desenvolver, a partir, também, das fotografias registradas e em acordo com o diretor da escola, atividades em diálogo com a comunidade escolar. Em momentos distintos, foram realizadas algumas atividades, a saber: oficina de formação continuada com os professores indígenas sobre ideias matemáticas de espaço, formas e medidas em construções arquitetônicas, construção de uma maquete de habitação guarani e uma mostra cultural de matemática e tradição guarani (Figuras 2, 3 e 4). 


\section{REAMEC \\ REVISTA DA REDE AMAZÖNICA DE EDUCAÇí
EM CIÉNCLASE MATEMATICA}

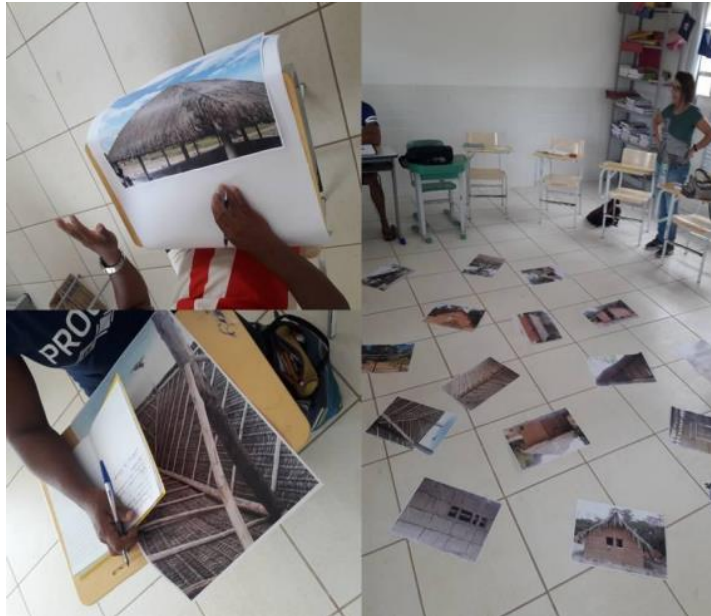

Figura 2 - Oficina de formação Fonte: acervo das pesquisadoras (2018)

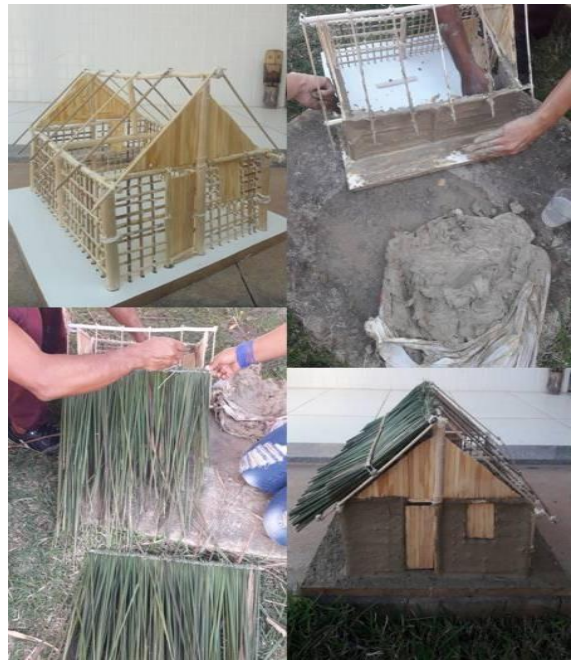

Figura 3 - Construção da maquete Fonte: acervo das pesquisadoras (2018)

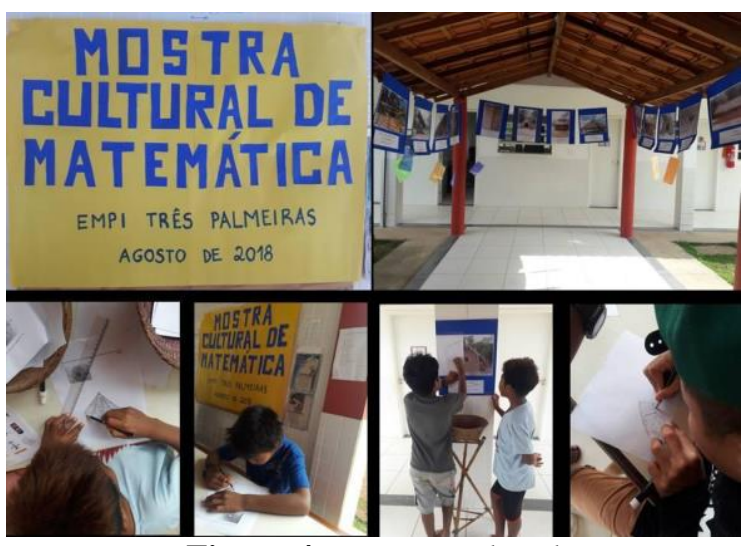

Figura 4 - Mostra cultural

Fonte: acervo das pesquisadoras (2018)

Os saberes compartilhados nesses momentos em espaços comunicativos foram de grande relevância à compreensão de aspectos relacionados às mba'eitxa oo djadjapo (técnicas de construções) dos Guarani Tambeopé em seus mais diversos significados. Em meio aos diálogos e observações, fomos produzindo significados que, acreditamos, vão ao encontro da realidade daquele povo.

A arquitetura guarani contempla o homem em seu sentido físico, com o conforto ambiental, mas também considera a proteção espiritual. A oo (casa de morada guarani) é referência de construção sustentável, visto que, por tradição, esse povo edifica utilizando materiais e técnicas de baixo impacto ambiental, em um processo de socialização entre as pessoas, pela sistematização do processo por meio da divisão de tarefas durante a construção, momento denominado mutirão. Elementos como o fogo no chão, o pisar a terra e a posição da casa em relação ao nascer do sol são marcantes na vivência guarani. Nas tekoa (terra apropriada para o Guarani; lugar para viver), hoje, ainda que, aos poucos, venham se 
transformando quanto aos antigos costumes e também com a utilização de materiais industriais, muitas casas continuam sendo erguidas com materiais construtivos tradicionais, como o barro, o bambu, a piaçava, o pindó, a taquara e o cipó.

As oo são, geralmente, pequenas construções de duas águas, feitas com bambu e/ou troncos mais grossos para sustentação. Estes são fincados no chão e amarrados com cipó ou embira, entrelaçando-se a outros mais finos, posicionados no sentido horizontal (hoje, é usado, por exemplo, o eucalipto, dado que é produzido na região e, ainda, pela escassez de outros materiais). As paredes são revestidas de barro, dando conforto térmico. O teto é feito com travessas de bambu ou madeira, revestidos com folha de pindó, piaçava ou sapê. Esses materiais facilitam a entrada da luz, a ventilação e a saída da fumaça causada pelo fogo dentro de casa - tradição entre os Guarani. As dimensões não são padrão, mas determinadas pela quantidade e estatura das pessoas que vão morar no espaço. A área interna da $o o$, em geral, não possui repartição e, quase sempre, tem duas portas, uma em cada extremidade.

Para uma melhor compreensão, deixamos como sugestão a leitura do "Guia Didático"s que elenca os materiais construtivos do povo Guarani Tambeopé.

\subsection{Na escola-campo do município de Vitória}

O primeiro contato entre a mestranda, a professora regente de Matemática e a gestora da Escola Municipal de Ensino Fundamental Arthur da Costa e Silva, situada no Bairro República, em Vitória, foi estabelecido em 2017, quando foram apresentados os objetivos da pesquisa e definidos os seus sujeitos, 22 estudantes da unidade de ensino que cursavam o $8^{\circ}$ ano do Ensino Fundamental e que aceitaram participar do estudo voluntariamente, assinando termos de compromisso.

Tendo em vista a temática que pretendíamos desenvolver, buscamos analisar quais os valores e significados os sujeitos da pesquisa possuíam em relação aos povos indígenas, na tentativa de capturar a perspectiva dos participantes e possíveis outras produções em momentos futuros. Por isso, a fim de darmos início ao planejamento voltado à intervenção curricular em Matemática, anteriormente ao nosso primeiro contato com a turma, disponibilizamos um questionário-diagnóstico ${ }^{6}$ com a preocupação de compreender as

\footnotetext{
${ }^{5}$ A pesquisa realizada para o Mestrado Profissional desenvolveu, além da dissertação, um kit didático, o qual é acompanhado de um guia, que pode ser acessado em: http://educapes.capes.gov.br/handle/capes/570343.

${ }^{6} \mathrm{O}$ instrumento se encontra na dissertação de Moura (2019). 
relações socioculturais estabelecidas pelos sujeitos não indígenas (participantes da pesquisa) a respeito dos indígenas.

Ao analisarmos a totalidade das respostas, percebemos que a maioria dos estudantes carregava consigo uma visão estereotipada (Figura 5), muitas vezes preconceituosa e quase sempre empobrecida dos indígenas - moram em ocas, pintam-se e vestem roupas de palha -, não reconhecendo a diversidade que existe entre esses povos.
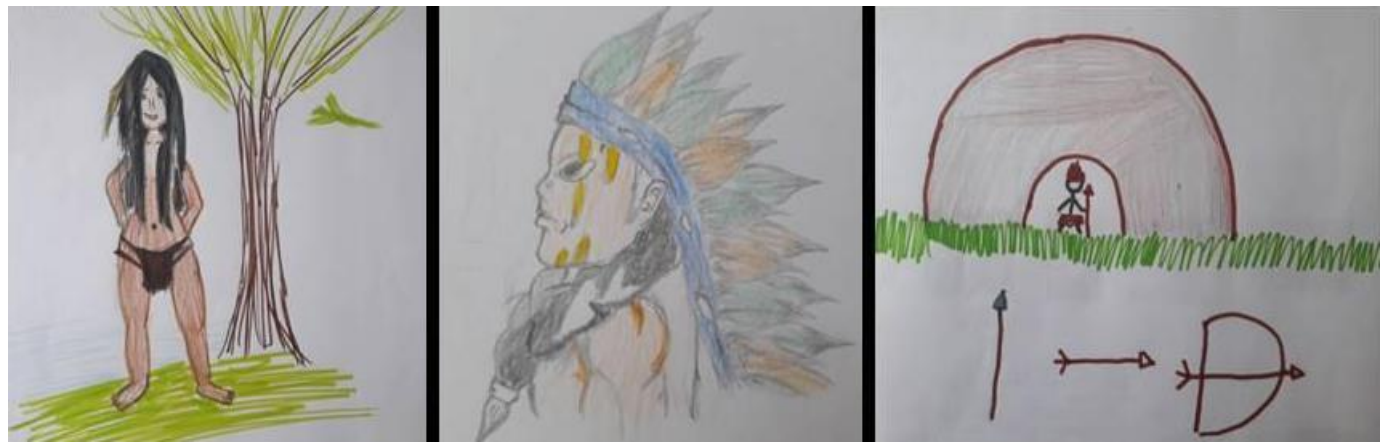

Figura 5 - Representações de indígenas feitas pelos estudantes em resposta ao questionário-diagnóstico Fonte: acervo das pesquisadoras (2018)

Percebemos também que os indígenas, em específico os povos do Espírito Santo, são desconhecidos para os alunos. E essa é a realidade de alunos que, mesmo residindo a poucos quilômetros de aldeias indígenas, desconhecem suas culturas, suas histórias, sua existência! Esse quadro é semelhante ao descrito por J. R. B. Freire (2002, p. 94):

\begin{abstract}
A quase totalidade da população brasileira jamais visitou uma aldeia indígena nem teve contato pessoal com qualquer índio. A representação que cada brasileiro tem do índio, como regra geral, é aquela que lhe foi transmitida na sala de aula pelo professor, com a ajuda do livro didático, e é reproduzida pela mídia. Dessa forma, cabe à escola uma grande responsabilidade na construção da imagem que os brasileiros têm sobre os índios e sobre si mesmos como produtos que são, entre outras, da matriz cultural indígena.
\end{abstract}

A concepção do indígena transmitida no ambiente escolar e reproduzida pela mídia traduz uma concepção estática da história, a qual Teao e Loureiro (2009, p. 60) descrevem como “[...] um índio-padrão: nu, de arco e flecha nas mãos”.

Esse primeiro levantamento e análise evidenciaram as relações socioculturais de mitificação pelos alunos não indígenas a respeito dos indígenas, a partir do que iniciamos o planejamento de elaboração de meios para estudo na aula de Matemática. Buscamos envolver 
elementos da cultura guarani, em um movimento dialógico com o próprio povo Guarani Tambeopé, e possibilitar a reflexão dos alunos sobre as realidades dos indígenas.

Nesse caminhar, planejamos a Unidade Didática ${ }^{7}$ (UD) de forma intencional e com possibilidade de recorrer a instrumentos que colaborassem para partilhar com os estudantes, de modo a promover com estes a (re)significação de saberes indígenas, além de seguir o currículo de Matemática legalmente prescrito ao oitavo ano do Ensino Fundamental, em conteúdos de geometria previstos, trabalhando elementos de construções guarani no Espírito Santo.

A UD planejada consiste em um conjunto de atividades orientadoras de ensino. No caso em questão, a UD foi programada para ser desenvolvida em 19 encontros (Figura 6), sendo "[...] composta por um conjunto de atividades articuladas que orientam as ações do professor e das crianças mediadas pelo conteúdo" (MOURA, 1996, p. 18).

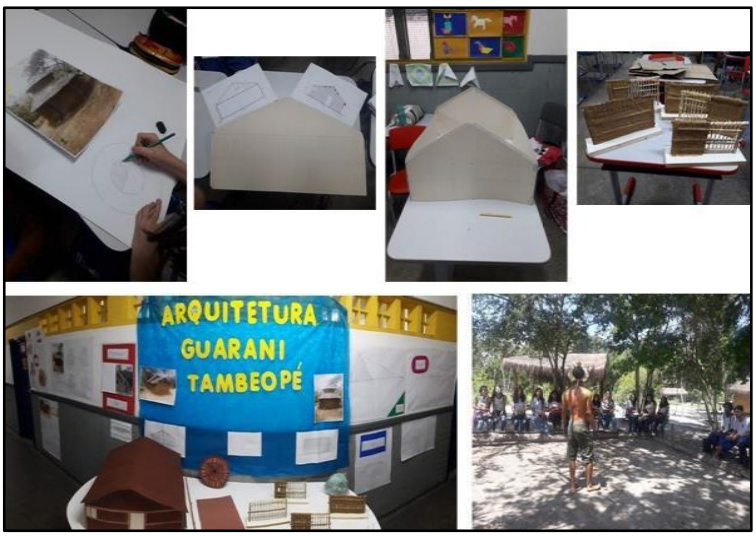

Figura 6 - Encontros e atividades realizadas Fonte: acervo das pesquisadoras (2018).

As atividades que compunham a UD, as quais, por vezes, perpassam os conteúdos da geometria escolar, foram elaboradas de forma a motivar o aluno com situações desafiadoras, despertar a sua curiosidade e estimular sua imaginação, para que visualizassem a Matemática no fazer prático e coletivo, visto que "o conhecimento matemático é construído pela criança no 'ato de fazer' por si mesma e na interpretação com os outros" (MOURA, 1996, p. 12). No entanto, vale ressaltar que a UD não teve por objetivo utilizar os aspectos das mba'eitxa oo djadjapo guarani como pretexto para um melhor desenvolvimento e compreensão das propriedades geométricas, ou seja, para o estudo da "nossa" Matemática escolar, nem como 
uma tentativa de buscar e identificar a "nossa" Matemática oculta nessas mba'eitxa oo djadjapo.

Não foi nosso objetivo utilizar os aspectos histórico-culturais guarani como prática matemática, visto que a matemática não é prática desse povo, mas de povos não indígenas. Não podemos dizer que seus significados preferenciais são da "nossa" Matemática, portanto, embora possamos lhes atribuir as mesmas palavras do universo da Matemática escolar, primeiramente, queremos mostrar a riqueza de valores e conhecimentos do próprio povo indígena.

Acreditamos na possibilidade de promover um diálogo entre diferentes matemáticas, de forma não hierarquizada e, ainda, que a escola é o lugar no qual esse diálogo pode fazer sentido, o lugar mais provável e seguro para que ele aconteça.

\section{ANÁLISE E RESULTADOS}

A análise dos resultados ${ }^{8}$ das ações pedagógicas desenvolvidas foi realizada considerando os atos dos alunos, relacionando-a com a metodologia de observações da sala de aula e relatórios produzidos pelos próprios alunos, fundamentada no referencial teórico já exposto.

Se o aluno não age/dialoga compartilhando legitimidades, não podemos analisar se ele produziu significados, que significados foram esses e se conseguimos partilhar o mesmo campo semântico. "Por isto é sempre preciso ler o aluno, saber onde ele está" (LINS, 2012, p. 27). Assim, as aulas foram planejadas e desenvolvidas no intuito de estabelecer espaços comunicativos propícios a observações, acreditando que a opção pela observação participante durante a implementação da UD permitiria obter dados relevantes à análise.

Nesse sentido, utilizamos dados provenientes de quatro tipos de procedimentos para a análise participante: (1) gravações em áudio de grupos de alunos em atividades em sala de aula; (2) observações escritas no diário de campo da mestranda; (3) relatórios escritos pelos alunos no decorrer dos dias; (4) fotografias registradas durante o desenvolvimento das ações em sala de aula - com autorizações que cumpriam aspectos éticos. Esse processo de intervenção aconteceu durante três meses, conforme os planejamentos da UD.

${ }_{8}^{8}$ A análise completa pode ser encontrada na dissertação de Moura (2019, p. 78-103). 
O material obtido foi sistematizado por meio de três unidades de análises interconectadas, para refletirmos a respeito dos benefícios da intervenção e avaliar se os objetivos da proposta foram alcançados, conforme segue.

\title{
4.1 Impactos e novidades
}

Foram observados os impactos causados nos alunos ao terem contato com outros significados de ser indígena hoje no Brasil. Isso porque, nos encontros que com eles tivemos, dialogamos sobre a existência de diferentes povos indígenas no país, vivendo em diferentes situações, disponibilizando-lhes imagens, ao que os alunos se mostraram surpresos com a diversidade e curiosos sobre os elementos das culturas indígenas.

Aluno: Professora, mas existe mais de um tipo de índio? Não é todo mundo igual, não?

Aluno: Que louco! A gente usa tanta palavra de índio e nem sabe. Sou capixaba e nem sabia que capixaba é palavra indígena!

(Diálogo dos alunos em sala9 ${ }^{9}$ 2019)

Muitos sentimentos foram surgindo ao longo de todo o processo. Em alguns alunos, os sentimentos foram observados explicitamente, enquanto em outros se manifestavam de forma mais sutil, permitindo o início de um diálogo entre culturas, sem hierarquização. "Não há também diálogo, se não há uma intensa fé nos homens. Fé no seu poder de fazer e de refazer. De criar e recriar. Fé na sua vocação de ser mais que não é privilégio de alguns eleitos, mas direito dos homens" (FREIRE, 2005, p. 93).

\begin{abstract}
Aluno: A aula foi massa! Agente descobrimos mais sobre os indígenas e nós adquirimos muito conhecimento. Assistimos um vídeo muito maneiro que a professora, depois, colocou no grupo e eu coloquei minha mãe pra vê. Mostrou que os tempos mudaram, os índios também. Mas eles continuam lutando pelo direito de ser índio.

Aluno: A professora contou da importância do fogo pra eles. Eles coloca fogo dentro de casa. Então, precisam fazer um esquema que não pega fogo na casa e nem sufoca eles com a fumaça. Eles constroem a casa junto com um ajudando o outro e isso é bem legal.

Aluno: Amarrar as madeirinhas e colocar a mão no barro pra fazer nossa parede foi até legal mais muito dificeis de fazer, deu uma trabalheira! São bem parecidos com outros de outras regiões que ela mostrou. Bem legal, isso!
\end{abstract}

(Relatório dos alunos, 2019)

9 As falas e os relatórios foram transcritos mantendo-se a integridade e respeitando-se a limitação de cada
estudante. 
Assim, além dos impactos apresentados, na próxima unidade de análise retratamos como os diálogos foram sendo estabelecidos, a (re)significação acontecendo e a confiança na validação do que estava sendo exposto e trabalhado, aos poucos, instaurando-se.

\subsection{Somos todos iguais/somos todos diferentes}

Assumimos a responsabilidade, de forma dialógica, de ampliar compreensões, mostrar que somos todos diferentes, que, porém, acreditamos ser possível promover um diálogo entre diferentes formas de matematizar e que a escola é o lugar no qual esse diálogo pode ser iniciado de forma mais segura e não hierarquizada. Desse modo, tornamo-nos todos semelhantes, o que, segundo Lins (1999, p. 80), significa "[...] sermos capazes de compartilhar um espaço comunicativo".

O diálogo intercultural foi, assim, uma questão central da intervenção. Desde o início, tínhamos a consciência de que deveríamos incentivá-lo e mostrar que, apesar de diferentes, podemos compartilhar um mesmo espaço comunicativo e que isso deveria acontecer para que, posteriormente, o reconhecimento e a valorização do povo Guarani pela turma se manifestasse por meio da enunciação.

Nessa direção, do primeiro ao último encontro, enquanto os conhecimentos matemáticos e guarani eram ampliados, sublinhávamos a necessidade de reconhecer a importância e o valor desse povo e seus fazeres e saberes, conhecendo-os sem buscar estabelecer uma relação de dependência entre conhecimentos. Esse reconhecimento de independência, todavia, não ocorreu rapidamente. Alguns educandos pareciam tratar os saberes/fazeres guarani somente como algumas atividades extras, transversais, enquanto que os conteúdos matemáticos abordados seriam unicamente escolares, como notamos nos relatos a seguir.

\footnotetext{
Aluno: Montamos e pintamos partes da maquete da casa de reza (opy) [em Tambeopé]. Trabalhamos com proporção, escala, grandezas e medidas corretas para ter uma casa correta. Aluno: O meu grupo fez o teto da oca. Nós usamos réguas, esquadro e também usamos o transferidor. Praticamos o recorte e também pintamos a oca, misturando cores para deixar mais realista. Tiramos medidas também para que o teto ficasse de acordo com a casa e montamos tudo no final.

(Relatório dos alunos, 2019)
}

Outros alunos tentaram estabelecer uma relação entre saberes desses povos relacionados à construção e a matemática escolar, tentativa natural perante a vivência com o sistema educacional ao qual estamos vinculados. 
Aluno: Meu grupo teve que fazê a frente da casa de reza. Acho que posso dizer que entendi pelo menos um pouco da relação entre a geometria e a cultura daquele indígena. A professora entregou a frente da casa num papel pra gente e agente teve que aumentar ela no papel mais forte e pintar depois também. Medimos cada ladinho com a régua pra ficar igual e percebi que a geometria tava exatamente naquilo. Sei que não tinha nome e é algo natural do cotidiano deles, mas é a nossa geometria. (Relatório dos alunos, 2019)

No entanto, com o decorrer dos encontros, os alunos foram compreendendo os saberes/fazeres guarani como significados próprios da cultura indígena. Em trechos de algumas de suas falas, destacadas dos relatórios por eles produzidos, notamos uma postura diferente quanto ao saber arquitetônico guarani.

Aluno: É incrivel que mesmo sem nenhum conhecimento de engenharia, eles, juntos, elaboram tantos jeitos de construir casas, e também casas diferentes [se referindo às de dois andares e redondas]. $\mathrm{Na}$ verdade, eles desenvolvem uma engenharia diferenciada, muito interessante e criativa.

(Relatório dos alunos, 2019)

O olhar com lentes da disciplina Matemática foi amenizado e deu espaço à compreensão das realidades de construção desse povo sem que fosse preciso usar as mesmas lentes, bem como ao reconhecimento e valorização dos indígenas.

\subsection{Enunciação e (re)significação}

O sujeito enuncia algo em que acredita aliando-o àquilo que ele entende que é autorizado a dizer, ou seja, ele constitui um conhecimento que consiste em uma crençaafirmação com uma justificação (LINS, 2012). Assim, como o principal objetivo era fomentar a (re)significação da cultura Guarani Tambeopé por meio da inserção de seus saberes/fazeres nas aulas de Matemática e já que “[...] a produção de significado acontece numa enunciação [...]” (LINS, 2012, p. 14), direcionamos nossos olhares aos discursos e produções semânticas (por meio de signos, símbolos, desenhos, expressões e ações) dos alunos.

Freire (2005) pontua não ser possível o diálogo sem o amor, a humildade e a fé nos homens, características afetivas que notamos nas falas dos alunos em distintos momentos, o que nos permite concluir que ocorreu uma (re)significação com as ações que realizamos em sala de aula, reconhecendo que os significados das ticas de matema do povo Guarani, em diferentes momentos, foram tidos como legítimos e valiosos nos âmbitos cultural e intercultural. Além disso, a "confiança nos homens" de que fala Freire (2005) instaurou-se no 
diálogo e permitiu uma relação horizontal, sem hierarquização, o que, por fim, possibilita gerar a solidariedade para a transformação e humanização mais globalizada.

\begin{abstract}
Aluno: Pessoal, eu amei a experiência de conhecer melhor a cultura de indígenas! Gostaria muito de ir pessoalmente para vivenciar seu modo de vida. Bom, des que o projeto Arquitetura Guarani começou, eu tive outra 'visão' sobre a cultura e o modo de vida deles, eu pude ver que são e tem muito mais a ensinar pra gente do que ao contrário, pude ver que o modo de vida deles não estão nos 'padrões' que tamos acostumandos por aqui na cidade. Fazendo a parede indígena, eu vi que vai muito além de barro e palha, tem uma estrutura por trás, como o modo que amarramos os barbantes, com medidas e tal. Eu pensei que não tinha um conhecimento por trás disso e eu estava completamente errada. Eles são povos como qualquer outro, dentro de um único país. O Brasil é caracterizado pela sua diversidade e a cultura indígena é só mais uma. Os índios tem fama de povos violentos mas isso não passa de um mito, eles lutam pelos seus direitos e na maioria das vezes também são pacíficos. Eles são julgados pelo modo de vida diferenciado. E isso tem que mudar!

(Diálogos dos alunos em sala, 2019)
\end{abstract}

Modificar o discurso alienado e também alienador e mostrar a diversidade de elementos culturais presente nas mba'eitxa oo djadjapo do Guarani Tambeopé foi, então, um importante meio de (re)significações. Essa ação pode indicar mais um passo no processo de reconhecimento e de valorização do povo Guarani Tambeopé por outros interlocutores, além dos muros da escola, visto que esses alunos, que antes precisavam da presença de outro "mais capaz" para fazer e falar algo a respeito dos indígenas, agora conseguem fazê-lo sozinhos.

Nessa perspectiva, verificamos que a produção de significados aconteceu em uma enunciação e os alunos, que no início do processo se constituíam como "leitores" de um "texto", ao final, tornam-se autores "prontos" para produzir novas enunciações na direção de outros "leitores". As ações pedagógicas, as reflexões e as produções foram todas pensadas, planejadas e desenvolvidas tendo esse como um dos objetivos. Portanto, consideramos que alcançamos resultados positivos e valiosos.

Vencer as dificuldades contribuiu para penetrar na sutileza necessária em termos da potencialização e análise dos resultados, somando ao nosso crescimento como pesquisadoras. Além disso, gerou um diálogo entre a teoria acadêmica com a prática educacional vivenciada, o qual se configurou como estímulo, no sentido de levar o estudante a perceber que é possível estabelecer relação entre ambas, a qual é exaltada pela afirmativa de Lins $(1999$, p. 92) de que a "Educação matemática que pratico não é nunca vista como uma preparação para a vida: ela já é vida".

Certamente foi no conflito em meio às adversidades que pudemos refletir sobre a prática como educadoras matemáticas naquele contexto e, de modo singular, sobre as transformações que a educação intercultural proporciona. 


\section{CONSIDERAÇÕES FINAIS}

A investigação da cultura Guarani Tambeopé contribuiu com a promoção de um diálogo crítico entre indígenas e não indígenas por meio dos distintos saberes e fazeres matemáticos dessas culturas, as quais, como tal, constituem-se historicamente. Temos prezado por esse diálogo quando adequadamente promovido, que mostra demasiada importância no contexto da educação escolar, uma vez que proporciona um cenário satisfatório para o fomento de uma percepção mais humanizada dos aspectos científicos.

A experiência com as construções arquitetônicas da cultura guarani permitiu que aflorassem significações pelas quais esse povo organiza e compartilha suas percepções de si, de sociedade e de mundo. Nesse processo, relacionar os saberes e fazeres desse povo, presentes em suas mba'eitxa oo djadjapo, com a "nossa" Matemática só faz sentido se seus significados forem compreendidos pelo viés histórico-cultural.

Compreender essas diferenças ao planejarmos ações a serem desenvolvidas em sala de aula implica não termos a pretensão de "transmitir significados", mas, sim, informações sobre as realidades indígenas como elas efetivamente são, para que, então, os educandos, de forma autônoma, produzam seus próprios significados e, consequentemente, ocorra também a produção de conhecimentos - (re)significando o ser [indígena] pelo conhecer [sua história, seus costumes].

Assim, com o desenvolvimento do projeto aqui relatado, alcançamos a comunidade escolar não indígena, que (re)significou e desmistificou a visão de que o indígena quase não alterou seu estilo de vida desde a chegada dos colonizadores. Além disso, foi possível estreitar laços harmoniosos de diálogo intercultural e trocas de saberes escolares entre as culturas indígenas e não indígenas do Espírito Santo.

Ainda que tenhamos trabalhado mais especificamente com a cultura Guarani Tambeopé, o alcance da pesquisa vai além: aponta caminhos que podem ser trilhados ou, pelo menos, algumas direções para o processo educacional, motivando provocações e reflexões sobre a prática docente quanto à sua responsabilidade por promover uma educação humanizadora.

Envolvemo-nos com essa temática imbuídas do compromisso que sentimos a partir dos nossos contatos com a realidade dos povos indígenas e cientes da diversidade brasileira. 
Concluímos com satisfação e alegria, na certeza de que novos caminhos nos foram abertos, como também novas maneiras de atravessá-los.

\section{REFERÊNCIAS}

BARTON, B. Dando sentido à etnomatemática: etnomatemática fazendo sentido. In: RIBEIRO, J. P. M.; DOMITE, M. C. S.; FERREIRA, R. (Orgs.). Etnomatemática: papel, valor e significado. Porto Alegre: Zouk, 2006. p. 39-74.

BRASIL. Lei $\mathbf{n}^{\circ}$ 11.645, 10 de março de 2008. Dispõe sobre as diretrizes e bases da educação nacional, para incluir no currículo oficial da rede de ensino a obrigatoriedade da temática História e Cultura Afro-Brasileira e Indígena. Brasília: 2008. Disponível em: http://www.planalto.gov.br/ccivil_03/_ato2007-2010/2008/lei/111645.htm. Acesso em: 3 mar. 2018.

CANCLINI, N. G. Diferentes, desiguais e desconectados. Tradução de Luiz Sérgio Henriques. 3. ed. Rio de Janeiro: Ed. UFRJ, 2009.

CARRINHO, R. G. Habitação de interesse social em aldeias indígenas: uma abordagem sobre o ambiente construído Mbyá-Guarani no litoral de Santa Catarina. 2010. 206 f. Dissertação (Mestrado) - Programa de Pós-Graduação em Arquitetura e Urbanismo, Universidade Federal de Santa Catarina, Florianópolis, 2010. Disponível em: https://repositorio.ufsc.br/handle/123456789/94054. Acesso em: 3 mar. 2018.

\section{CARVALHO, M. L. Tempo, aspecto e modalidade na língua Guaraní Mbyá}

(TAMBEOPÉ). 2013. 197 f. Dissertação (Mestrado) - Programa de Pós-Graduação em Linguística, Universidade de Brasília, Brasília, 2013. Disponível em: https://repositorio.unb.br/handle/10482/13414. Acesso em: 3 mar. 2018.

D’AMBROSIO, U. Educação Matemática: da teoria à prática. 21. ed. Campinas: Papirus, 2010.

D’AMBROSIO, U. Etnomatemática: elo entre as tradições e a modernidade. 2. ed. Belo Horizonte: Autêntica, 2007.

D'AMBROSIO, U. Introdução. In: FERREIRA, M. K. L. (Org.). Madikauku - os dez dedos das mãos: matemática e povos indígenas no Brasil. Brasília: MEC, 1998. p. 11-14.

FLICK, U. Introdução à pesquisa qualitativa. Tradução de Joice Elias Costa. 3. ed. Porto Alegre: Artmed, 2009.

FREIRE, J. R. B. A imagem do índio e o mito da escola. In: MARFAN, M. A. (Org.). Congresso Brasileiro de Qualidade na Educação - Formação de Professores: educação escolar indígena. Brasília: MEC, 2002. p. 93-99.

FREIRE, P. Pedagogia do oprimido. Rio de Janeiro: Paz e Terra, 2005.

LEONTIEV, A. O desenvolvimento do psiquismo. Lisboa: Livros Horizonte, 1978. 
LIBÂNEO, J. C. Pedagogias e pedagogos, para quê? São Paulo: Cortez, 2008.

LINS, R. C. O modelo dos campos semânticos: estabelecimentos e notas de teorizações. In: ANGELO, C. L. et al. (Org.). Modelo dos campos semânticos e educação matemática: 20 anos de história. São Paulo: Midiograf. 2012. p.11-30.

LINS, R. C. Por que discutir teoria do conhecimento é relevante para a educação matemática. In: BICUDO, M. A. V. (Org.). Pesquisa em educação matemática: concepções e perspectivas. São Paulo: Ed. Unesp, 1999. p. 75-94.

LÜDKE, M.; ANDRÉ, M. E. D. A. Pesquisa em educação: abordagens qualitativas. 2. ed. Rio de Janeiro: EPU, 2013.

MOURA, A. P. A. Saberes Guarani Tambeopé em aulas de matemática da Educação Básica: um olhar etnomatemático às suas mba'eitxa oo djadjapo. 2019. 130 f. Dissertação (Mestrado) - Programa de Pós-Graduação em Educação e Ciências e Matemática, Instituto Federal do Espírito Santo, Vitória, 2019. Disponível em:

https://sucupira.capes.gov.br/sucupira/public/consultas/coleta/trabalhoConclusao/viewTrabalh oConclusao.jsf?popup=true\&id trabalho=8251704. Acesso em: 16 mar. 2020.

MOURA, M. O. A atividade de ensino como unidade formadora. Bolema, Rio Claro, v. 11, n. 12, p. 29-43, 1996. Disponível em:

https://www.periodicos.rc.biblioteca.unesp.br/index.php/bolema/article/view/10647/7034.

Acesso em: 14 jul. 2018.

MOURA, M. O. et al. A Atividade orientadora de ensino como unidade entre ensino e aprendizagem. In: MOURA, M. O. (Org.). A atividade pedagógica na teoria HistóricoCultural. Brasília: Liber Livro, 2016. p. 93-125.

RIGON, A. J.; ASBABR, F. S. F.; MORETTI, V. D. Sobre o processo de humanização. In: MOURA, M. O. (Org.). A atividade pedagógica na teoria Histórico-Cultural. Brasília: Liber Livro, 2010. p. 15-50.

SILVA, M. M.; RIBEIRO, J. P. M.; FERREIRA, R. Biopirataria e explorações ocorridas no Brasil: um relato-denúncia de práticas criminosas contra povos indígenas. REAMEC - Rede Amazônica de Educação em Ciências e Matemática, v. 9, n. 1, e21031, jan./abr., 2021. Disponível em: https://periodicoscientificos.ufmt.br/ojs/index.php/reamec/article/view/11668. Acesso em: 22 jun. 2021.

SILVA, R. M. N. B. Negro e Ensino Médio: representações de professores acerca de relações raciais no Currículo. Belém: Ed. UFPA, 2009.

TEAO, K. M.; LOUREIRO, K. História dos índios do Espírito Santo. Vitória: Ed. do Autor, 2009. 


\section{NOTAS}

\section{AGRADECIMENTOS}

Aos Guarani Tambeopé, em primeiro lugar, pelo grande exemplo de vida e pela práxis corajosa recriada a cada dia, pela acolhida, amizade e o grande aprendizado, que levaremos por toda a vida. A professora de matemática Leandra Gonçalves dos Santos (in memorian), da escola não indígena, por ter apoiado esse projeto juntamente com a direção escolar, o que propiciou a participação dos alunos. Ao Grupo de Pesquisas em História da Matemática e Saberes Tradicionais e Grupo de Estudos e Pesquisa em Modelo dos Campos Semânticos e Educação Matemática, do Instituto Federal de Educação do Espírito Santo.

\section{FINANCIAMENTO}

Financiado pelo(s) próprio(s) autor(es).

\section{CONTRIBUIÇÕES DE AUTORIA}

Resumo/Abstract/Resumen: Ana Paula Azevedo Moura

Introdução: Ana Paula Azevedo Moura

Referencial teórico: Ana Paula Azevedo Moura

Análise de dados: Ana Paula Azevedo Moura

Discussão dos resultados: Ana Paula Azevedo Moura

Conclusão e considerações finais: Ana Paula Azevedo Moura

Referências: Ana Paula Azevedo Moura

Revisão do manuscrito: Claudia A. C. de Araujo Lorenzoni e Ligia Arantes Sad

Aprovação da versão final publicada: Ana Paula Azevedo Moura, Claudia A. C. de Araujo Lorenzoni e Ligia Arantes Sad.

\section{CONFLITOS DE INTERESSE}

Os autores declararam não haver nenhum conflito de interesse de ordem pessoal, comercial, acadêmico, político e financeiro referente a este manuscrito.

\section{DISPONIBILIDADE DE DADOS DE PESQUISA}

O conjunto de dados que dá suporte aos resultados da pesquisa foi publicado no próprio artigo.

\section{CONSENTIMENTO DE USO DE IMAGEM}

Não se aplica.

\section{APROVAÇÃO DE COMITÊ DE ÉTICA EM PESQUISA}

A pesquisa foi aprovada pelo Comitê de Ética em Pesquisa com seres humanos (Número do Parecer: 2.697.182). Certificado de Apresentação de Apreciação Ética (CAAE nº 86170518.8.0000.5072), gerado pela CONEP (Número do Parecer: 2.867.129) para o projeto de pesquisa do qual este artigo é oriundo.

\section{COMO CITAR - ABNT}

MOURA, Ana Paula; SAD, Ligia Arantes; LORENZONI, Claudia A. C. de Araujo. Matemáticas e Arquitetura Guarani Tambeopé: uma investigação na Educação Básica. REAMEC - Rede Amazônica de Educação em Ciências e Matemática. Cuiabá, v. 9, n. 2, e21044, maio a agosto, 2021. https://doi.org/10.26571/reamec.v9i2.12263

\section{COMO CITAR - APA}

Moura, A. P., Sad, L. A., \& Lorenzoni, C. A. C. de A. (2021). Matemáticas e Arquitetura Guarani Tambeopé: uma investigação na Educação Básica. REAMEC - Rede Amazônica de Educação em Ciências e Matemática, 9(2), e21044l. https://doi.org/10.26571/reamec.v9i2.12263

\section{LICENÇA DE USO}

Licenciado sob a Licença Creative Commons Attribution-NonCommercial 4.0 International (CC BY-NC 4.0). Esta licença permite compartilhar, copiar, redistribuir o manuscrito em qualquer meio ou formato. Além disso, permite adaptar, remixar, transformar e construir sobre o material, desde que seja atribuído o devido crédito de autoria e publicação inicial neste periódico. 
DIREITOS AUTORAIS

Os direitos autorais são mantidos pelos autores, os quais concedem à Revista REAMEC - Rede Amazônica de Educação em Ciências e Matemática - os direitos exclusivos de primeira publicação. Os autores não serão remunerados pela publicação de trabalhos neste periódico. Os autores têm autorização para assumir contratos adicionais separadamente, para distribuição não exclusiva da versão do trabalho publicada neste periódico (ex.: publicar em repositório institucional, em site pessoal, publicar uma tradução, ou como capítulo de livro), com reconhecimento de autoria e publicação inicial neste periódico. Os editores da Revista têm o direito de proceder a ajustes textuais e de adequação às normas da publicação.

\section{PUBLISHER}

Universidade Federal de Mato Grosso. Programa de Pós-graduação em Educação em Ciências e Matemática (PPGECEM) da Rede Amazônica de Educação em Ciências e Matemática (REAMEC). Publicação no Portal de Periódicos UFMT. As ideias expressadas neste artigo são de responsabilidade de seus autores, não representando, necessariamente, a opinião dos editores ou da referida universidade.

\section{EDITOR}

Dailson Evangelista Costa (iD)

\section{HISTÓRICO}

Submetido: 28 de abril de 2021.

Aprovado: 23 de junho de 2021.

Publicado: 02 de agosto de 2021. 